\title{
LA HUELLA DE LAS MIGRACIONES EN EL METABOLISMO DEMOGRÁFICO DEL ÁREA METROPOLITANA DE BARCELONA
}

\author{
Andreu Domingo \\ Centre d'Estudis Demogràfics/CERCA \\ adomingo@ced.uab.es \\ ORCID iD: https://orcid.org/0000-0003-3270-1939 \\ Jordi Bayona-i-Carrasco \\ Profesor Lector Serra Húnter, Departament de Geografia (Universitat de Barcelona) y Centre d’Estudis Demogràfics/CERCA \\ jordibayona@ub.edu \\ ORCID iD: https://orcid.org/0000-0003-2819-9085
}

Recibido: 11/03/2021; Aceptado: 07/11/2021; Publicado: 10/12/2021

Cómo citar este artículo/citation: Domingo, Andreu; Bayona i Carrasco, Jordi (2021). La huella de las migraciones en el metabolismo demográfico del Área Metropolitana de Barcelona. Estudios Geográficos, 82 (291), e083. https://doi.org/10.3989/estgeogr.202194.094

RESUMEN: La teoría del "metabolismo demográfico" da cuenta del cambio social a través de la sucesión de las diferentes generaciones en un territorio determinado. Recientemente se ha recuperado de forma prospectiva para relacionar las características sociodemográficas de la inmigración internacional con el reemplazo generacional. En nuestro caso, aplicamos esta perspectiva sobre el territorio de forma retrospectiva usando el Registro de Población de Cataluña, con el objetivo de analizar la composición por género, generación y origen de las personas que viven en los diferentes barrios de la ciudad de Barcelona y en los distritos del resto de su área metropolitana (AMB), teniendo en cuenta su procedencia. En particular, centramos la atención en tres generaciones: 1956-1960, 1976-1980 y 1986-1990, seleccionadas por su particular evolución demográfica en el AMB en los últimos decenios. Su análisis nos permite, por una parte, caracterizar mejor el barrio en cuanto a la composición de la población por origen, sexo y edad que habita en ella. Por otro lado, podemos reinterpretar la convivencia (y segregación) de los residentes de cada área estudiada, como condición previa para el contacto intercultural teniendo en cuenta la edad, el sexo y el nivel de estudios, además del lugar de nacimiento y procedencia, como habitualmente se hace.

PALABRAS CLAVE: Metabolismo demográfico, Inmigración, Diversidad, Barrio, Área Metropolitana de Barcelona.

\section{THE FOOTPRINT OF MIGRATION ON THE DEMOGRAPHIC METABOLISM OF THE BARCELONA METROPOLITAN AREA}

ABSTRACT: The theory of "demographic metabolism" accounts for social change through a succession of generations in a certain territory. It has recently been prospectively recovered to relate the sociodemographic characteristics of international immigration with generational replacement. In our case, we retrospectively apply this perspective on territory using the Population Register of Catalonia in order to analyse the composition by gender, generation, and origin of people living in the different neighbourhoods of the city of Barcelona and districts in the rest of its metropolitan area (MAB), taking into account the neighbourhood or district and place of origin. In particular, we focus on three generations: 1956-1960, 1976-1980 and 1986-1990, selected for their particular demographic evolution in the MAB in recent decades. This enables us to give a better description of the neighbourhood in terms of composition of the resident population by origin, sex, and age. Moreover, we can reinterpret cohabitation (and segregation) of residents in each area studied as a condition of intercultural contact, taking into account age, sex, and educational level, as well as origin and birthplace, which is usually the case.

KEY WORDS: Demographic metabolism, Immigration, Diversity, Neighbourhood, Metropolitan Area of Barcelona. 


\section{INTRODUCCIÓN: METABOLISMO DEMOGRÁFICO, TERRITORIO Y MIGRACIÓN}

Entendemos por metabolismo demográfico la sucesión de las generaciones en un territorio determinado, mediante sus componentes clásicas: nacimientos, defunciones y migraciones. Dicho término, ha sido rescatado por el demógrafo Wolfgang Lutz (2012) como predictor de los cambios sociales a partir de la composición cambiante de los individuos que integran las diferentes generaciones o cohortes, en referencia a ciertas características sociodemográficas mesurables. Explícitamente se refiere al nivel de instrucción, o a los valores expresados por creencias, como los sentimientos identitarios o la religión.

Aunque el demógrafo austriaco insista en que su aportación a la teoría respecto a autores anteriores es considerar por un lado la posibilidad de evolución dentro de las cohortes ya establecidas -aludiendo, por ejemplo, al reciclaje formativo o la formación continuada-, y, por el otro, subrayar la heterogeneidad interna de las cohortes, no es difícil adivinar en el corazón de su construcción teórica, en el contexto demográfico en el que es enunciada, el trasfondo del miedo a la substitución etno-cultural y religiosa de la población autóctona por la inmigrada, en mayor o menor medida concordante con la teoría de la Tercera transición demográfica postulada por David Coleman (2006 y 2015). Es así como el ejercicio de proyecciones derivado de esa conceptualización se ha centrado primordialmente en el factor religioso directamente ligado a la presencia de inmigración musulmana en países de raigambre cristiana (Goujon, Skirbekk, Fliegenschnee y Strzelecki, 2006), o en el conjunto del planeta (Pew Research Centre, 2015), y en la formación del capital humano, debido a los contrastes en el nivel de instrucción (Lutz, Butz y Samir, 2014; Lutz y Muttarak, 2017).

Como antecedente del uso del concepto de "metabolismo demográfico" y su efecto en el cambio social se remite a la lectura que el demógrafo norteamericano Norman B. Ryder realizó en los años sesenta (Ryder, 1965), siguiendo el trabajo clásico de Karl Mannheim sobre las generaciones (1928). La reflexión de este último representó en su momento un esfuerzo por sintetizar la aproximación positivista y la historicista en boga a caballo entre el siglo XIX y el XX, donde, sea dicho de paso, ya se consideraba la diversidad dentro de una misma posición generacional al distinguir entre "conexión generacional" y "unidad generacional". Perteneciendo a una generación austrohúngara nacida a finales del siglo XIX (1883), cuando escribe su trabajo sobre las generaciones, en 1928 , los factores de heterogeneidad que tiene en mente no son los aportados por la migración internacional, sino la que se produce a partir de la dicotomía rural/urbano en el caso de la conexión generacional -constatando las diferencias a una misma edad-, o de las ideologías en el de su unidad -agrupando diferentes edades-. Deberemos esperar a la segunda mitad del siglo XX para ver cómo se consideran las migraciones y el territorio, de hecho, Norman Ryder puso entonces la urbanización como ejemplo de cambio social promovido por la atracción en un mismo espacio de sucesivas cohortes de jóvenes (Ryder, 1965). Sin embargo, la reflexión teórica del autor -en pleno baby boom-, se inclina por considerar el crecimiento natural como la aportación fundamental en la constitución y tamaño de las generaciones, decantándose más por el análisis de las edades y de las instituciones en la socialización de los individuos, que por el impacto en el espacio o la disrupción que dentro de las cohortes podían representar las migraciones. Aunque trabajos posteriores se han planteado el efecto del tamaño de las generaciones en su ciclo vital, en la alternancia de generaciones llenas y vacías, como los realizados por Richard A. Easterlin en los Estados Unidos (Easterlin, 1980), pocos han sido los que se han aproximado al nivel infraestatal o los que se han centrado en el impacto de las migraciones. En las sociedades desarrolladas contemporáneas, caracterizadas por el envejecimiento, donde la migración se ha convertido en la piedra angular de la evolución de la población, resulta fundamental atender al concepto de metabolismo demográfico en relación al cambio social, tanto debido a la velocidad a la que se suceden las generaciones, como al incremento de la diversidad intergeneracional -esto es, entre diferentes generaciones-, así como intrageneracional -dentro de una misma generación- (Striessnig, 2019). Así, además del nivel de instrucción o de la religión ya comentados, se ha tratado el cambio en dimensiones tan diversas como las mutaciones culturales y la identidad (Striessnig y Lutz, 2016) o las actitudes frente al género y la homosexualidad (Brooks y Bolzendahl, 2014; Andersen y Fetner, 2008; y, Pampel, 2016).

España constituye un caso de extremo interés en este campo, ya que por un lado desde la Transición democrática destaca por el viraje de actitudes y comportamientos demográficos de las diferentes generaciones implicadas durante el último cuarto del siglo XX en ese proceso, mientras que al mismo tiempo encarna la aparente paradoja de la ralentización de la sucesión de las generaciones debido al extraordinario alargamiento de la esperanza de vida y al descenso de la fecundidad. Por 
el contrario, conoce una aceleración a partir de la alta intensidad de las migraciones -que aumenta tanto la diversidad intrageneracional como la intergeneracional-, durante el nuevo milenio, siendo en los tres fenómenos un paradigma respecto a otros países. A pesar del interés mencionado, los estudios en España sólo han tocado indirectamente esta dinámica. Por ejemplo, al tener en cuenta la provisión de alumnos por lugar de origen o nacionalidad en las escuelas (Bayona, Domingo y Menacho, 2020), o la cadena de vacantes que en la vivienda ha producido el proceso de envejecimiento (Módenes y López-Colás, 2014), siguiendo los pasos de Dowell Myers y Sung Ho Ryu (2008).

Nuestra intención, no es la previsión, sino una mirada retrospectiva en la escala territorial inframunicipal que nos permita constatar la huella de las migraciones en el metabolismo demográfico en dos sentidos: 1) Dar cuenta del impacto de las migraciones en los efectivos y la diversidad inter e intrageneracional en la ciudad y el Área Metropolitana de Barcelona desde 2000 a 2019, medida por el lugar de nacimiento, el nivel de instrucción y el índice de masculinidad; y 2) Desde la perspectiva espacial poder analizar la distribución de las diferentes generaciones y sus características en el territorio. Tanto el primer como el segundo abordaje, resultan de gran interés para la implementación de políticas municipales, dibujando el primero una cartografía de la exposición a la diversidad como condición previa al potencial intercultural, mientras que la segunda permite caracterizar los espacios inframunicipales en relación tanto a la migración como a la sedentarización de sus habitantes, con una tipología más compleja que la resultante del cálculo del simple porcentaje de personas nacidas fuera de España o del municipio o por nacionalidad.

\section{FUENTES DE DATOS Y METODOLOGÍA}

En este trabajo se han empleado datos derivados del Registro Continuo de población de Cataluña, cedidos por el Institut d'Estadística de Catalunya (Idescat), que incorporan además de los datos habituales del Padrón Continuo de población (sexo, edad, lugar de nacimiento, nacionalidad y lugar de residencia), el año de llegada al lugar de residencia actual y el nivel de instrucción. Como área de estudio, se analiza el continuo urbano de la ciudad de Barcelona, identificado como el Área Metropolitana de Barcelona (AMB), unidad metropolitana conformada por 36 municipios y con 3,29 millones de residentes en 2019. La unidad inframunicipal utilizada es el barrio para la ciudad de L'Hospitalet de Llobregat, y los distritos en los municipios que disponen de ellos.
En el caso particular de la ciudad de Barcelona el nivel de detalle es mayor, ya que se emplean las Áreas Estadísticas Básicas (AEB), que dividen la ciudad en 233 subáreas. En conjunto, el $A M B$ se divide en nuestro análisis en un total de 356 subáreas, con una media de población de alrededor de diez mil personas.

El análisis que se plantea en este trabajo es generacional, y se emplean tres cortes temporales, 2002, 2008 y 2018. El año 2002 es el primero con este nivel de detalle en el Registro continuo de Población, y se sitúa en el período inicial del crecimiento de las migraciones internacionales en España. El año 2008 marcó el comienzo de la crisis económica, mostrando los últimos efectos del crecimiento, mientras que 2018 es el último del que se disponían datos en el momento de realizar la demanda al Idescat, recogiendo un segundo boom migratorio que se produjo entre 2014 y 2019. En estos tres cortes temporales se analiza con un mayor grado de detalle a tres generaciones, las nacidas en 1956-1960, 1976-1980 y 1986-1990, seleccionadas por su particular evolución demográfica en el AMB en los últimos decenios. La generación 1956-1960 es la última que registrar un incremento importante de efectivos debido a la migración interior desde España, la 1976-1980 es la primera con un impacto destacado de la inmigración internacional a inicios de siglo, y la 1986-1990 es la última cuyos datos nos permiten un análisis en dos cortes temporales, además de conocer la recuperación de la inmigración internacional posterior a la recesión de 2008. En el año 2002 las tres generaciones tienen respectivamente 42-46 años, 22-26 años y 12-16 años, que en 2018 se trasladan a 58-62, 38-42 y 28-32 años.

El crecimiento demográfico de los efectivos generacionales lleva asociado un incremento de la diversidad, que podemos observar si atendemos por ejemplo al lugar de nacimiento o al nivel de instrucción. Una de las formas más habituales de determinar el grado de diversidad es mediante el empleo del índice de diversidad de Simpson (Simpson, 1949). Es un indicador originado en los estudios de ecología, empleado para medir la biodiversidad, entendida cómo el número de especies presentes en relación con su abundancia relativa en un ecosistema (White, 1986). La fórmula utilizada para el cómputo del índice es la siguiente:

$$
I D S=\frac{1}{\sum_{i=1}^{S} P(i)^{2}}
$$

Donde $\mathrm{P}(\mathrm{i})$ se refiere al porcentaje que representa cada uno de los subgrupos (i) sobre el total. En este caso, se ha empleado subdividiendo a la población en 
ocho grupos en función de su lugar de nacimiento: nacidos en el mismo municipio, en otro municipio de la provincia, en el resto de Cataluña, en el resto de España y en el extranjero, en este último caso diferenciando según la agrupación continental de los principales orígenes (Europa, África, América y Asia). El resultado puede oscilar entre 1 (un único grupo alcanza el 100\% de los individuos) y 8 (todos los grupos tienen el mismo peso).

En el análisis del nivel de instrucción se considera a la población agrupada en 3 grandes grupos (sin estudios, primarios más secundarios, y superiores), de los cuales analizamos los estudios superiores, cuya posesión muestra fuertes disparidades entre los años analizados y en su distribución territorial, además de en la edad y el origen. Se reconstruye el nivel de estudios con el Censo de 2001 y el de 2011, más los datos derivados del Registro Estadístico de la Población de 2018. En este último caso se considera que la cobertura del nivel de estudios alcanzado es suficientemente buena para las generaciones más jóvenes, no así para las de más edad.

En último lugar, el incremento de la diversidad se medirá también en función de la composición por sexo de las generaciones, aplicando el índice de masculinidad, ratio que relaciona el volumen de hombres en relación al de mujeres, multiplicado por 100 . Valores por encima de 100 indican una mayor presencia masculina, y por debajo una mayor proporción de mujeres.

\section{LA EVOLUCIÓN DE LOS EFECTIVOS GENERACIONALES}

Las grandes áreas urbanas son un buen ejemplo de metabolismo demográfico si consideramos el papel de las migraciones, tanto internas como internacionales, en la renovación de su población. El análisis que aquí presentamos se centra en el Área Metropolitana de Barcelona, continuum urbano de $636 \mathrm{~km}^{2}$ con 3.291.654 habitantes en 2019, la mitad de ellos, 1.636.762 residentes en la ciudad central, y el resto en 35 municipios metropolitanos, con elevadas intensidades de las migraciones metropolitanas internas e internacionales durante las últimas décadas.

En primer lugar, se estudia el tamaño de las generaciones y su evolución desde 1960. En ausencia de migraciones la evolución de los efectivos de las generaciones es obviamente decreciente debido a la mortalidad. Todo incremento de los mismos debe imputarse a la aportación migratoria, en concreto al saldo migratorio. En primer lugar, se analiza la ciudad central, Barcelona, y el resto provincial. ${ }^{1}$ Desde esta perspectiva, se observa como las dinámicas varían enormemente entre centro y periferia, tanto en las generaciones más antiguas como en las más recientes (Fig. 1). El mayor aumento relativo registrado en la periferia de la generación 1956-1960 responde a los últimos coletazos de la migración interior en España, llegada durante los sesenta e inicios de los setenta, y que se asientan alrededor de la ciudad de Barcelona, ya que esta se encontraba saturada y apenas crecía su población (Pujadas, 2007). Hasta los años 2000 esta generación sigue aumentando en la periferia mientras desciende en la ciudad central, situación que se justifica por la continuidad en el proceso de suburbanización, de salida del centro metropolitano, tanto por las dificultades de acceso a la vivienda como por el cambio en las preferencias residenciales (Bayona y Pujadas, 2014). Como consecuencia, y en el resto provincial, se llegan a doblar los efectivos iniciales de esta generación. En la generación siguiente, 19661970, se disipa el efecto de las migraciones interiores debido a su finalización, pero sigue constatándose el resultado de la suburbanización, especialmente entre los años 2000 y 2010, coincidiendo con las edades de emancipación de esta generación y los años de mayor intensidad del boom inmobiliario. Así, se percibe un descenso de los efectivos generacionales en el centro metropolitano y un crecimiento de la periferia, aunque con incidencias muy por debajo de las de la generación precedente.

La dinámica del resto de generaciones, en contraste, debe ser interpretada desde otra perspectiva, $y$ tomando en consideración la profunda huella que deja la migración internacional. Es por ello que los crecimientos son más substanciales en la ciudad central que en la periferia, ya sea porqué se añaden a generaciones menos numerosas debido a la baja fecundidad de la ciudad central en comparación con la periferia metropolitana (Pujadas, Bayona, Gil y López, 2013), ya sea por el papel de atracción inicial respecto los flujos migratorios internacionales de la gran ciudad, que experimenta proporciones de población nacida en el extranjero muy superiores al resto provincial. Con ello, y especialmente entre las mujeres, algunas generaciones vuelven a duplicar su volumen, como sucede en los nacidos en 1986-1990 y 1991-1995. El crecimiento en el resto provincial sigue siendo apreciable, aunque de menor intensidad, con un aumento de alrededor de un $50 \%$ del volumen de partida. La crisis económica, y el incipiente retorno o las migraciones secundarias hacia otros territorios, aún pueden ser contemplados en algunas generaciones en el resto provincial (la ge- 
FIGURA 1.

EVOLUCIÓN DEL TAMAÑO DE LAS GENERACIONES, 1960-2019 (GENERACIONES AL NACIMIENTO = 100)

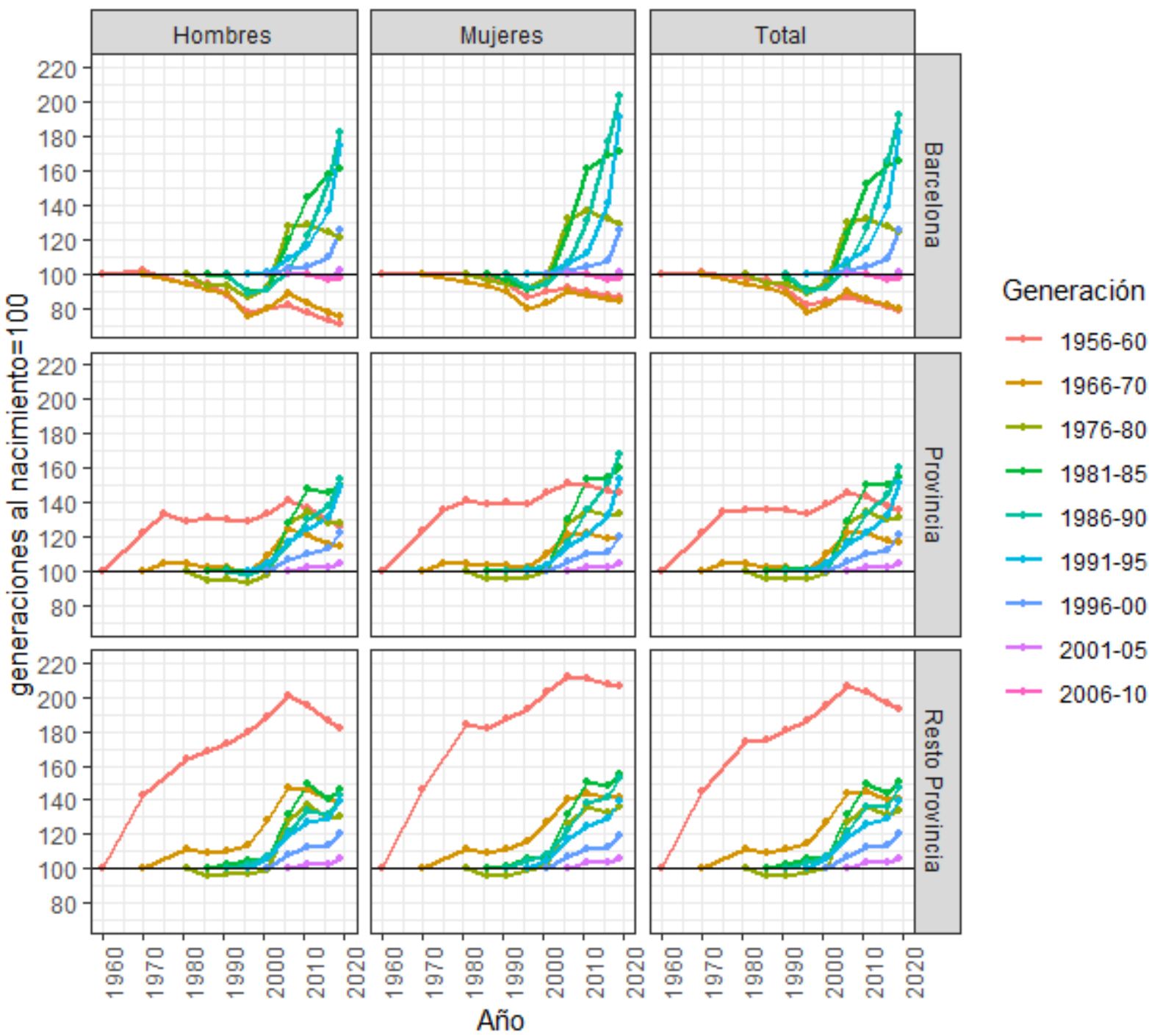

Fuente: Censos y padrones, con datos del Instituto Nacional de Estadística (INE). Elaboración propia.

neración 1986-1990, por ejemplo), donde descienden los efectivos, no así en la ciudad central.

\section{LA DIVERSIDAD POBLACIONAL: GÉNERO, GENERA- CIÓN E INMIGRACIÓN}

Las tres generaciones seleccionadas tienen características muy distintas entre ellas, que se derivan del momento en que nacieron y de la evolución demográfica y social posterior. Así, la generación 1956-1960 que protagonizó el inicio del baby boom en España es una generación con un número de efectivos iniciales elevado (con nacimientos en Cataluña que pasan de los 60 mil de 1956 a los 70 mil de 1960, y un Índice Sintético de Fecundidad ascendiente, de 1,92 a 2,23 hijos por mujer según datos de Cabré y Pujadas, 1987) y que además conoció grandes crecimientos durante sus primeros años relacionados con la migración interna en España, donde Barcelona y su provincia constituía uno de los principales focos de atracción (Ortega y Solana, 2015). Territorialmente, estos incrementos se produjeron fuera de la ciudad central, ya que el centro metropolitano se encontraba saturado y se situaba en sus máximos de población, siendo la evolución muy distinta entre centro y periferia. Es una generación que llega a la edad adulta en plena transición democrática -por ello nos referiremos a ella como la "Generación de la Transición democrática"-, y que se ve afectada en su juventud por la crisis econó- 
mica de los setenta, que en España fue especialmente gravosa a finales de la década en las zonas más industrializadas. Es protagonista, además, de los primeros descensos de la fecundidad y de notables alteraciones en las pautas de constitución familiar. Durante los 16 años analizados, entre 2002 y 2018 , sufre un decrecimiento de su volumen, pasando de 206656 efectivos en 2002 a 191565 en 2018, 15091 personas menos y un descenso acumulado del 7,3\%. Es una de las primeras generaciones donde se visibiliza el aumento en el número de nacidos en el extranjero, aunque en menor medida que en las generaciones posteriores. Así, de representar el 8,6\% de los efectivos en 2002 pasa al $13,8 \%$ en 2018 . Este aumento se produce durante los primeros años, alcanzando un $14,3 \%$ en 2008 , para descender más tarde con la crisis.

La siguiente generación analizada es la de 19761980, la que pasó a popularizarse como "Generación X" y que algunos autores llaman también "Generación @” por ser la primera en la que impacta la migración digital (Feixa, 2021). Es de las primeras en reducir su volumen por el descenso de la fecundidad, en comparación a generaciones precedentes (de 112 mil nacimientos en 1975 a 82 mil en 1980 en Cataluña, y con un ISF que disminuye de 2,86 a 1,90 en los mismos años). Se caracterizan por haber nacido en plena transición y crisis económica, con un aporte de la migración interior limitado, representando en este aspecto un cambio significativo respecto a la composición por orígenes de las generaciones anteriores. Su juventud transcurre en un ciclo de crecimiento económico, a diferencia de la generación anterior y posterior, padeciendo a pesar de ello, los efectos negativos del boom inmobiliario (Gutiérrez y Delclós, 2015) correspondiéndose con las edades de emancipación, siendo protagonistas destacados del proceso de suburbanización en la búsqueda de una vivienda asequible. Es una generación donde se incorpora un elevado número de inmigrados extranjeros a inicios de siglo XXI, ya que es cuando coinciden con las edades de mayores intensidades migratorias. Así, en 2002 son 251253 residentes, con un 10,6\% nacidos en el extranjero, pero también con un $36,7 \%$ de la población que había cambiado de municipio dentro de la misma provincia. En 2008 aumenta rápidamente su volumen hasta alcanzar los 297507 efectivos (un 18,4\% más), con 97485 personas y el 32,8\% nacidos en el extranjero. En los diez últimos años, sin embargo, sufre una dinámica regresiva, manifestándose el impacto de la crisis económica, la desaceleración e incluso el retorno, perdiendo a 16 mil personas, alrededor del $5 \%$ de los efectivos de 2008, una parte de ellos de origen extranjero (7 mil residentes menos), situándose en 281230 individuos.

FIGURA 2

COMPOSICIÓN DE LA POBLACIÓN POR GENERACIÓN Y ORIGEN, Y EVOLUCIÓN DEL ÍNDICE DE DIVERSIDAD

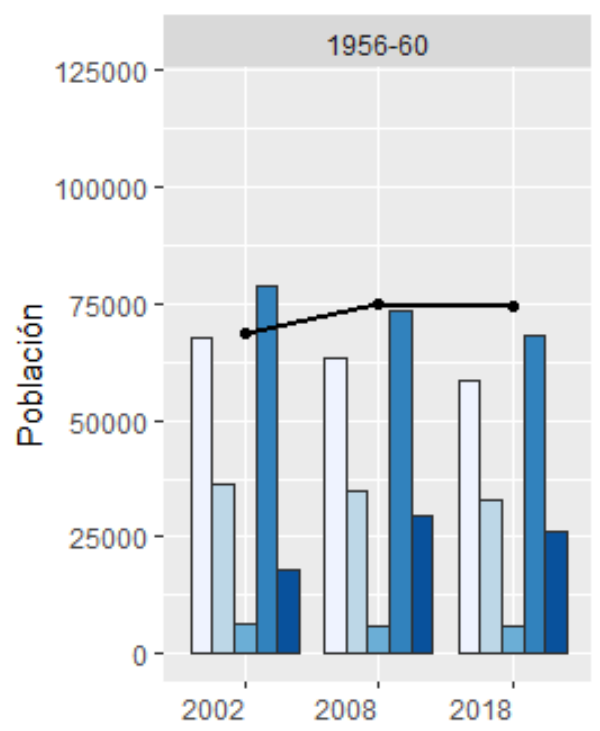

Mismo municipio

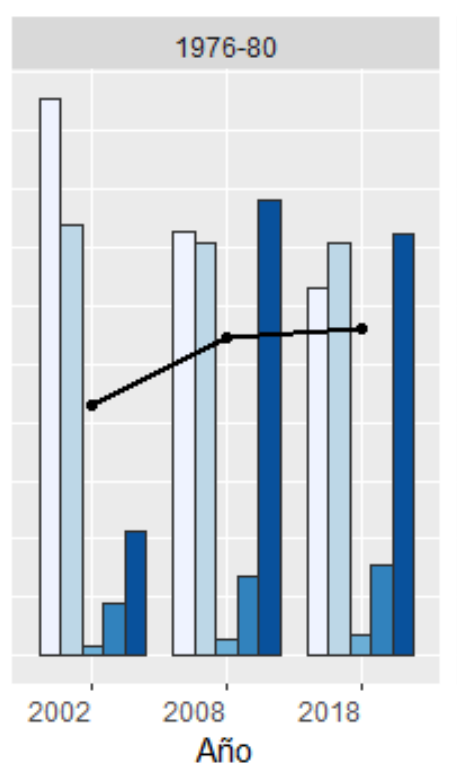

Resto Cataluña

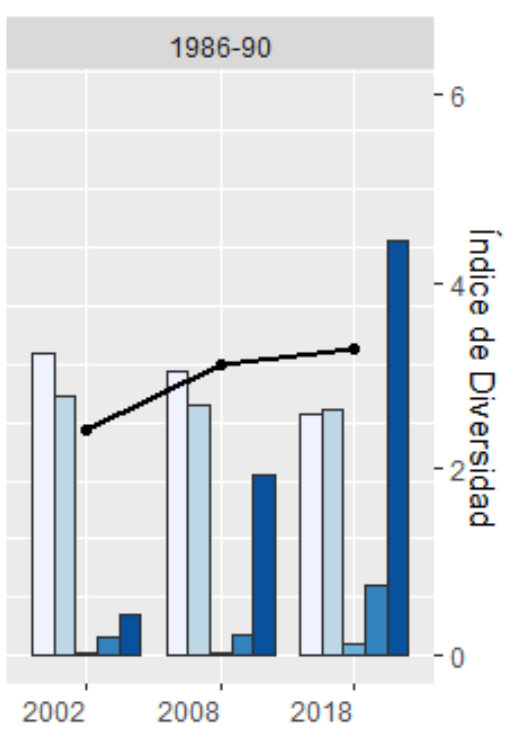

Resto España

Extranjero 
FIGURA 3.

EVOLUCIÓN DEL ÍNDICE DE DIVERSIDAD POR EDAD, AÑO Y GENERACIÓN, AMB, 2002-2018

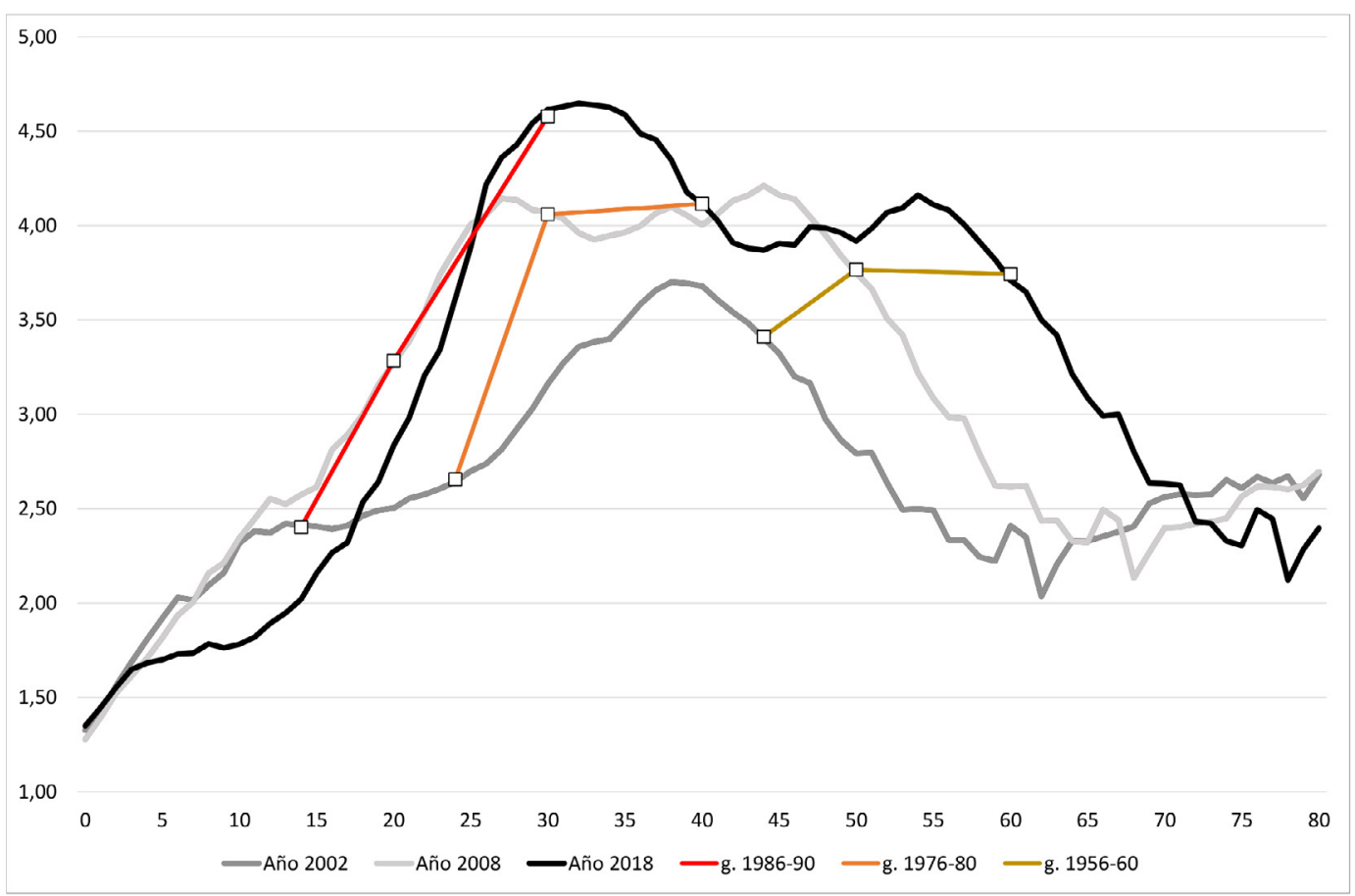

Fuente: Padrón de población, 2002, 2008 y 2018, con datos del Idescat. Elaboración propia.

La última generación analizada es la de 1986-1990, los que hoy conocemos como "Milennials", siendo caracterizada asimismo como "Generación \#" (Feixa, 2021), teniendo en cuenta su protagonismo en los movimientos de protesta como el $11 \mathrm{M}$. Es una generación que nace en momentos de muy baja fecundidad (1,24 hijos por mujer en 1990 en Cataluña, y una natalidad descendente, de 60 mil nacimientos en 1986 a 56 mil en 1990), y que en 2002 cuenta con 133629 efectivos en el AMB. Su tamaño es prácticamente la mitad que la generación de 1976-1980, con la que apenas se llevan diez años. Seis años más tarde, en 2008 , debido al boom migratorio internacional ha aumentado en volumen hasta alcanzar los 158624 residentes (un $18,7 \%$ más), con la incorporación de 30 mil personas nacidas en el extranjero (figura 2). La llegada de inmigrantes significa la suma de efectivos a edades muy jóvenes, representando un cuarto de esta generación. La promesa de progresión en su juventud se verá truncada por la gran recesión de 2008. En 2018 sigue con su crecimiento, ahora con 211376 efectivos (un 33,2\% más), con un nuevo fuerte aumento de los nacidos en el extranjero (que alcanzan las 89 mil personas y el $42,1 \%$ de esta generación) pero también de los nacidos en el resto de España (de apenas 3895 en 2002 a 14979 en 2018). A pesar de que se trata de un período temporal donde la crisis económica ha sido predominante, las generaciones jóvenes siguen viendo crecer su heterogeneidad interna debido a la aportación migratoria, que además adquiere un peso considerable al tratarse de generaciones con pocos efectivos.

Si atendemos al cálculo de la diversidad analizada por lugar de nacimiento (Fig. 2), las generaciones más antiguas parten de una mayor intensidad de la diversidad. Entre 2002 y 2008 la diversidad aumenta, especialmente para la generación 1976-1980, por los efectos ya mencionados de la inmigración internacional. Entre 2008 y 2018 el indicador se estabiliza para las dos generaciones de mayor edad, en cambio en la generación 1986-1990 se observa un fuerte crecimiento. Edad, momento y tamaño de la generación se interrelacionan, variando la causa principal de la diversidad, determinada primero por las migraciones interiores en España, más tarde por las dinámicas de suburbanización y, desde inicios de siglo XX, por la inmigración internacional.

El análisis etario permite examinar los distintos recorridos migratorios generacionales, resumidos a través del indicador de diversidad, que muestra un perfil por edad que experimenta fuertes variaciones 
(Fig. 3). Actualmente, es alrededor de los 30-35 años de edad donde la diversidad es máxima, producto de una inmigración internacional bastante heterogénea por orígenes (Galeano y Bayona, 2016) que se asienta sobre unas generaciones que contaban con pocos efectivos iniciales. Existe una segunda moda alrededor de los 50 años de edad, en una generación que en 2002 mostraba la máxima diversidad, al coincidir en unas mismas edades los últimos migrantes internos, las migraciones suburbanas y los primeros migrantes internacionales. Entre 2002 y 2008 aumenta el indicador en la mayoría de edades, especialmente entre las más jóvenes, mientras que entre 2008 y 2018 el incremento es menor, siendo únicamente significativo entre los más jóvenes, como ocurre en la generación 1986-1990. Al mismo tiempo, la diversidad a una misma edad resulta muy distinta. Los jóvenes de 2018 son mucho más diversos que los de 2008, pero ambos mucho más que los de 2002, cuando la inmigración internacional tenía un peso menor. Estas transformaciones contrastan con la estabilidad encontrada en las edades mayores, cuando la migración internacional y las migraciones internas no tenían la intensidad que adquirieron con posterioridad. La diversidad es cada vez mayor a edades más jóvenes, y entre los de mayor edad el paso de las generaciones representa también un crecimiento de la diversidad. Con ello, en la actualidad no es hasta los setenta años de edad que se registra un nivel bajo de diversidad.

Un segundo elemento que interviene en el aumento de la pluralidad es el derivado de los cambios en los niveles de instrucción de la población, y de los más jóvenes en particular. Además de la composición por origen, estas generaciones más jóvenes se caracterizan por unos niveles de instrucción mucho más elevados que las precedentes a la misma edad. Así, en el año 2018, la generación 1986-1990 presenta un porcentaje de jóvenes, entre los 28 y los 32 años, con estudios superiores del $47 \%{ }^{2}$, muy por encima de la registrada históricamente entre los jóvenes de la AMB. De esta forma los milennials mejoran las proporciones de estudios universitarios de las generaciones anteriores, ya hayan nacido en el extranjero (un $44,3 \%$ de ellos con estudios superiores) como en el mismo municipio donde siguen residiendo hoy en día (un 51,2\% con estudios universitarios). Con datos del Censo de noviembre de 2001, equiparables al Padrón de enero de 2002, la generación 1956-1960 obtenía un 21\% de estudios superiores, por un 25,3\% la de 1976-1980, que en aquellos años tenía entre 22 y 26 años de edad y en la que aún no todos sus efectivos habían acabado con su recorrido formativo. Pasada una década, y con datos del Censo de 2011, esta última generación alcanza el 39,8\% de estudios superiores. A edades similares, los jóvenes en la actualidad muestran proporciones de estudios superiores más elevadas, aunque esto se produce en un contexto marcado por la polarización: la tasa de abandono escolar prematuro registrada en España sigue siendo la más elevada entre países de la Unión Europea (un 17,3\% de jóvenes entre 18 y 24 años en 2019 había interrumpido sus estudios, un $19 \%$ en Cataluña). De esta forma, los porcentajes de jóvenes sin estudios más allá de los obligatorios y con estudios superiores se encuentran por encima de la media europea (Albaigés y FerrerEsteban, 2012). Es decir, ha crecido tanto la diferencia respecto a las generaciones anteriores, como la heterogeneidad interna en cada generación.

Finalmente, un tercer componente que experimenta también un cambio diferenciador dentro y fuera de los grupos generacionales se debe a la composición por sexo. Representado el índice de masculinidad (que relaciona el volumen de hombres y mujeres a una misma edad), es perceptible el influjo de las migraciones sobre la relación entre sexos. En su ausencia, se espera que dibuje una línea descendente, por la proporción más alta de hombres al nacimiento y la superior supervivencia femenina. En cambio, y como producto de las migraciones, en la Figura 4 se muestra cómo para el año 2018 existe un desequilibrio entre sexos que se manifiesta en una presencia creciente de mujeres y que se da para todos los grupos nacidos fuera de la provincia de Barcelona (Fig. 4, derecha).

Esta feminización de los efectivos es evidente entre los nacidos en el resto de Cataluña a todas las edades, mientras que entre los nacidos en el resto de España o en el extranjero se constata especialmente en las edades más jóvenes. Como resultado, entre los 20 y 34 años de edad la presencia de mujeres es superior en el conjunto de la población. Sin embargo, en 2002 y especialmente en 2008 este resultado derivado del arribo de inmigrantes internacionales funcionaba en el sentido opuesto, y supuso un mayor incremento de los hombres y con ello del índice de masculinidad. Si en 2002 se encontraban 94,8 mujeres jóvenes entre 20 y 34 años por cada cien hombres de su misma edad, en 2018 esa proporción había pasado a ser de 101,8 mujeres. Con todo, debemos llamar la atención sobre la composición por orígenes, así en 2018, entre los nacidos en el municipio o en otro municipio de Barcelona se presentaba una escasez relativa de mujeres en ese grupo de edad $(93,1$ y 96,1 mujeres por cada cien hombres respectivamente), compensada 
FIGURA 4.

ÍNDICE DE MASCULINIDAD POR EDAD Y LUGAR DE NACIMIENTO, AMB, 2002-2018

Evolución 2002-2018

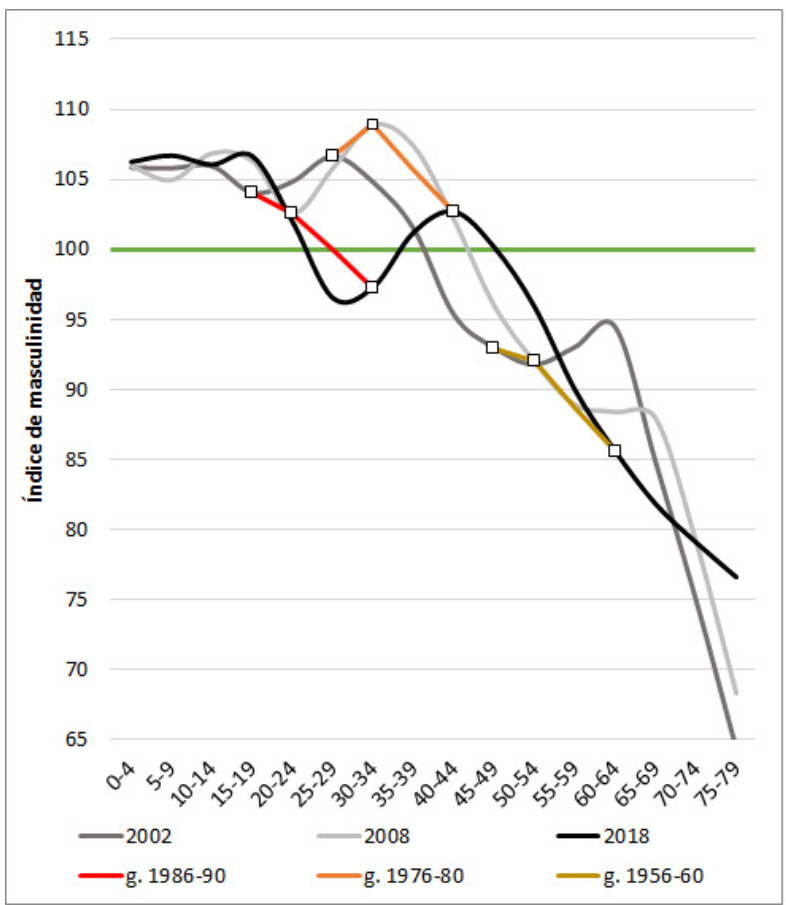

Fuente: Elaboración propia, Padrón de población, 2018, con datos del Idescat.

por las emigradas del resto de Cataluña $(123,2)$, España $(115,4)$ o del extranjero $(110,4)$, pareciendo que el mercado matrimonial dentro del AMBw fuera especialmente propicio a las uniones mixtas. Al mismo tiempo es de destacar que esa escasez de mujeres es la tónica general entre la adolescencia (de los 15 los 19 años), sin cambios desde el nacimiento, y la edad adulta (de los 35 a los 49 años). Así pues, las distintas características entre los flujos migratorios internacionales actuales y pasados, con perfiles muy distintos por sexo y edad de algunos orígenes, comportan un nuevo aumento de las diferencias entre generaciones, diferencias que no obstante, se manifestarán de forma muy distinta en el territorio.

\section{LA DIVERSIDAD POBLACIONAL EN LOS BARRIOS}

Finalmente abordamos estos cambios a una escala mayor y más fina, la del barrio. Las unidades territoriales a escala inframunicipal van a ser analizadas, en primer lugar, dependiendo de la presencia y la variación en los efectivos generacionales residentes en los mismos entre los años 2002 y 2018 (Fig. 5) y de sus consecuencias en la composición medida a partir de la diversidad (Fig. 6 y 7), para posteriormente centrar la
2018 (por lugar de nacimiento)

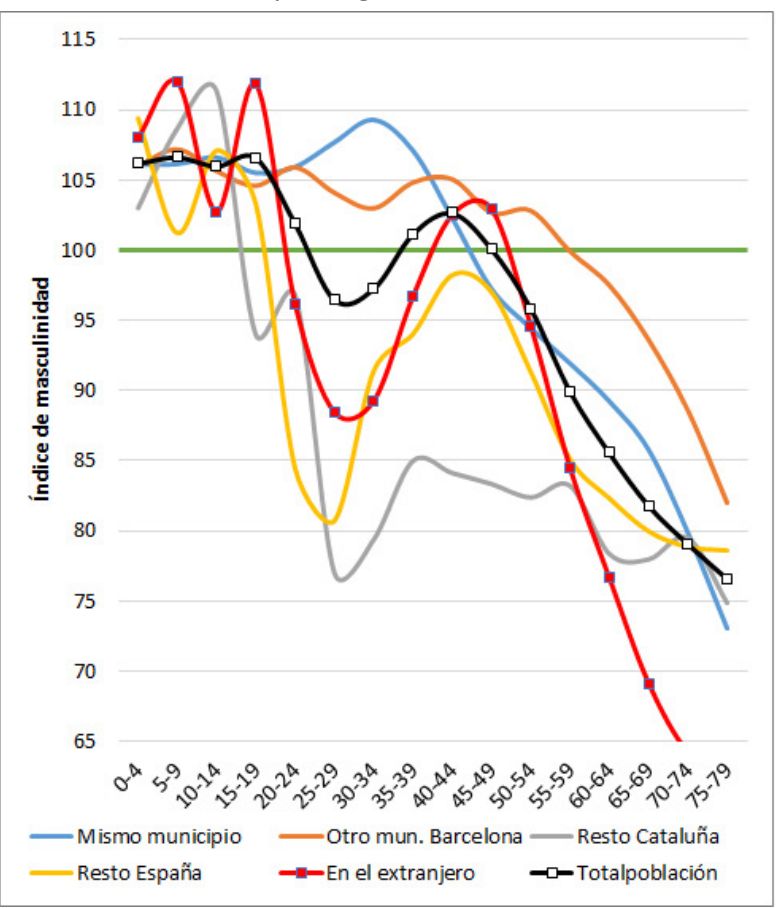

atención en lo que sucede según el nivel de estudios y el equilibrio entre sexos (Fig. 8 y 9). En los resultados del primer cálculo descubrimos como las tres generaciones analizadas han tenido un recorrido desigual dentro del AMB. La generación 1956-1960, por ejemplo, es una generación que protagoniza el proceso de suburbanización, alcanzando elevadas salidas de los municipios densos y centrales hacia la periferia metropolitana, lo que modifica su implantación en el territorio, y en particular en las zonas centrales, donde en 2018 encontramos menos del $75 \%$ de los efectivos presentes en 2002. Territorialmente es la que registra variaciones de menor magnitud, entre 2002 y 2018 apenas 45 zonas de las 356 analizadas tienen crecimientos significativos, algunas de ellas de desarrollo urbanístico reciente, localizándose el aumento de efectivos en áreas periurbanas donde domina el hábitat disperso en urbanizaciones, mientras que el decrecimiento es generalizado y se agudiza en el caso histórico de Barcelona, en las Áreas Estadísticas Básicas (AEB) de Ciutat Vella (Fig. 5). Una parte significativa de la merma en el número de residentes se produce por una emigración interna que supera los límites del $\mathrm{AMB}$, y se localiza en el resto de la región metropolitana, mucho más extensa. 
FIGURA 5.

EVOLUCIÓN DE LOS EFECTIVOS GENERACIONALES EN EL TERRITORIO METROPOLITANO, 2002-2018, AMB.
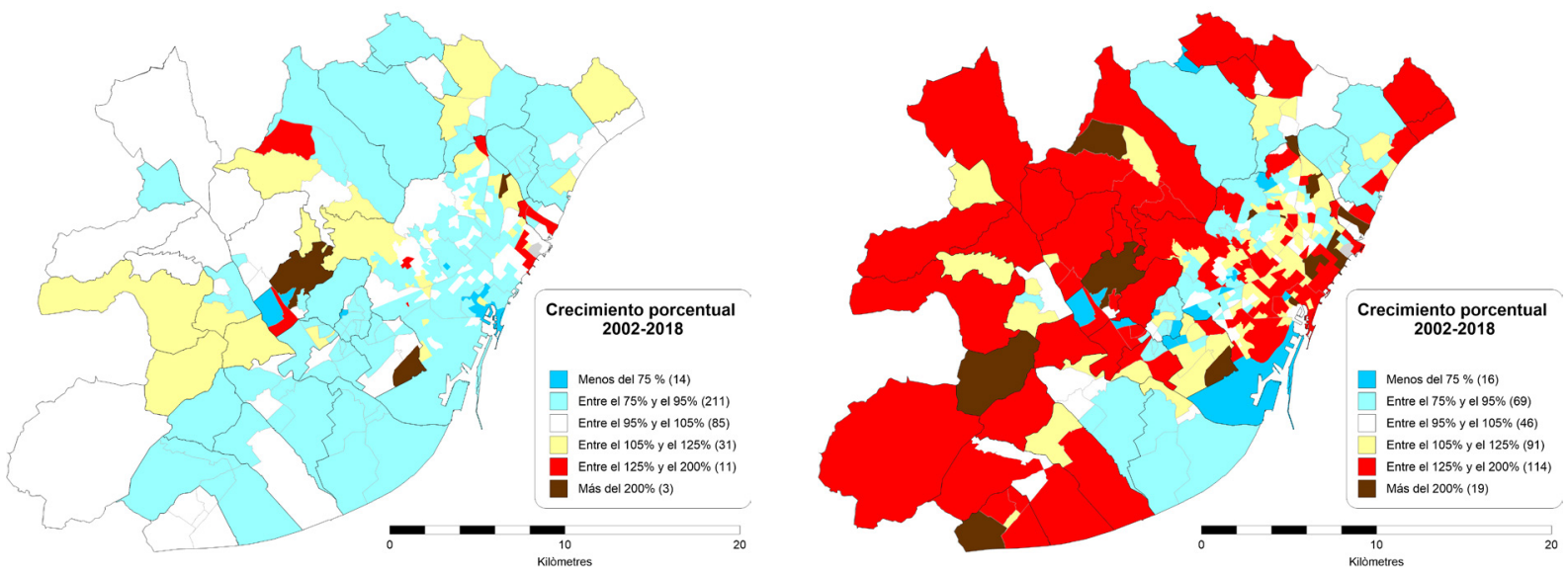

Generación 1986-1990

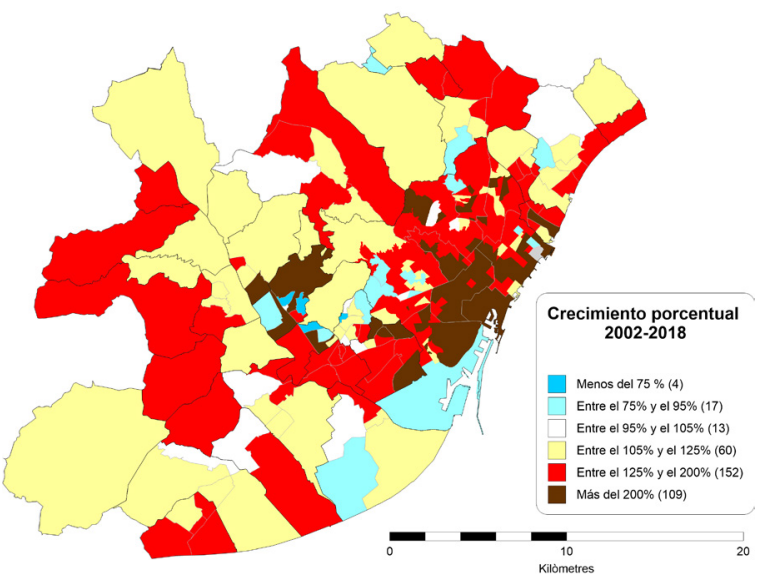

Fuente: Elaboración propia, Padrón de Población 2002 y 2018, con datos del Idescat.

Al mismo tiempo, la generación 1976-1980 experimenta un crecimiento en sus efectivos que se produce selectivamente en el territorio, al igual que en la generación anterior, los mayores aumentos se localizan fuera de la ciudad central, aunque esta vez con una intensidad mucho mayor. Los municipios de rentas bajas de la primera corona metropolitana, como Santa Coloma de Gramenet, Sant Boi de Llobregat o El Prat de Llobregat, son una excepción, ya que este incremento no se produce, con descensos también en algunos barrios periféricos de Barcelona, ya se sitúen entre los de mayor renta (en Sarrià Sant Gervasi) como entre los de renta inferior (en zonas de Nou Barris). Como resultado, hasta 224 áreas conocen crecimientos elevados, mientras que los descensos más significativos se concentran en tan sólo 16 de ellas.

Por último, el fuerte crecimiento del volumen de la generación 1986-1990 se visibiliza de forma extensa en el territorio. En contraste con las dos generaciones anteriores, se da una clara concentración de los efectivos en la ciudad de Barcelona, especialmente alrededor de los distritos centrales de Ciutat Vella y del Eixample, donde los integrantes de esta cohorte se llegan a duplicar con facilidad, pero también en Gràcia, Sants-Montjuïc o 
el Poblenou. La cuantiosa llegada reciente de migrantes internacionales a partir de 2014, después de superar la gran recesión de 2008 y coincidiendo con una incipiente recuperación económica anterior a la pandemia de la Covid-19, justifica en parte esta evolución, a la que se añadirían los cambios residenciales internos. Así, ciertos espacios centrales de la ciudad han protagonizado procesos de gentrificación (López, Sales, Solana, Fernández y Peralta, 2019), atrayendo con mayor intensidad que otras áreas a jóvenes de la generación milennials.

En la Figura 6 se muestra el índice de Simpson a esta misma escala para los tres períodos analizados y las tres generaciones que se han tenido en cuenta. En ella se constata la evolución de la diversidad para una misma generación a lo largo del tiempo. Como resultado de las distintas dinámicas migratorias la distribución, evolución y pluralidad de las generaciones es muy distinta en el territorio metropolitano. En general se produce un crecimiento de la diversidad entre 2002 y 2018 para los tres casos, especialmente entre las generaciones más jóvenes. A pesar de ello, en algunos barrios la diversidad apenas aumenta o hasta llega a descender: un elevado número de población inmigrada puede llegar incluso a significar un descen-

FIGURA 6.

DIVERSIDAD SEGÚN GENERACIÓN Y AÑO A ESCALA INFRAMUNICIPAL, AMB, 2002-2018

Gen. 1986-90 (12-16 años) Gen. 1976-80 (22-26 años) Gen. 1956-60 (42-46 años)
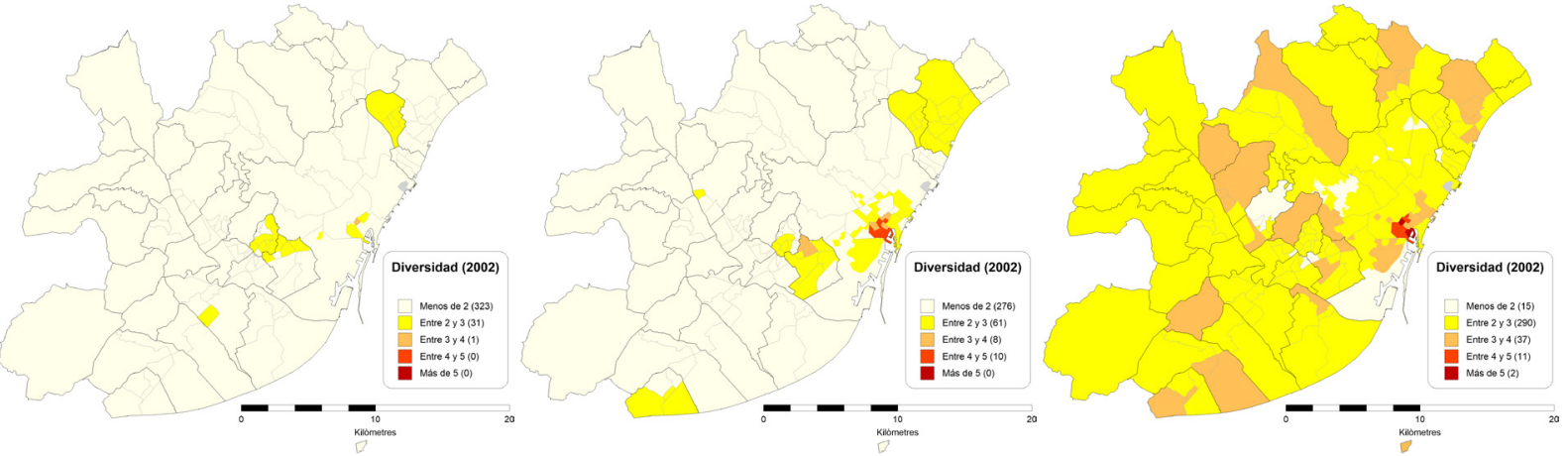

Gen. 1986-90 (18-22 años) Gen. 1976-90 (28-32 años) Gen. 1956-60 (48-52 años)
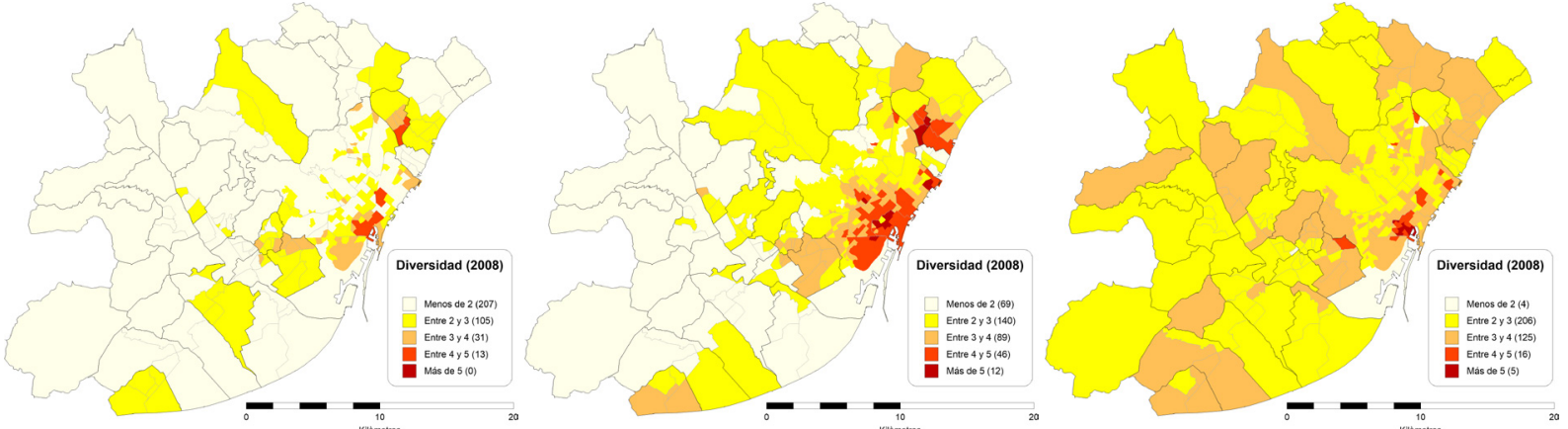

Gen. 1986-90 (28-32 años) Gen. 1976-80 (38-42 años) Gen. 1956-60 (58-62 años)
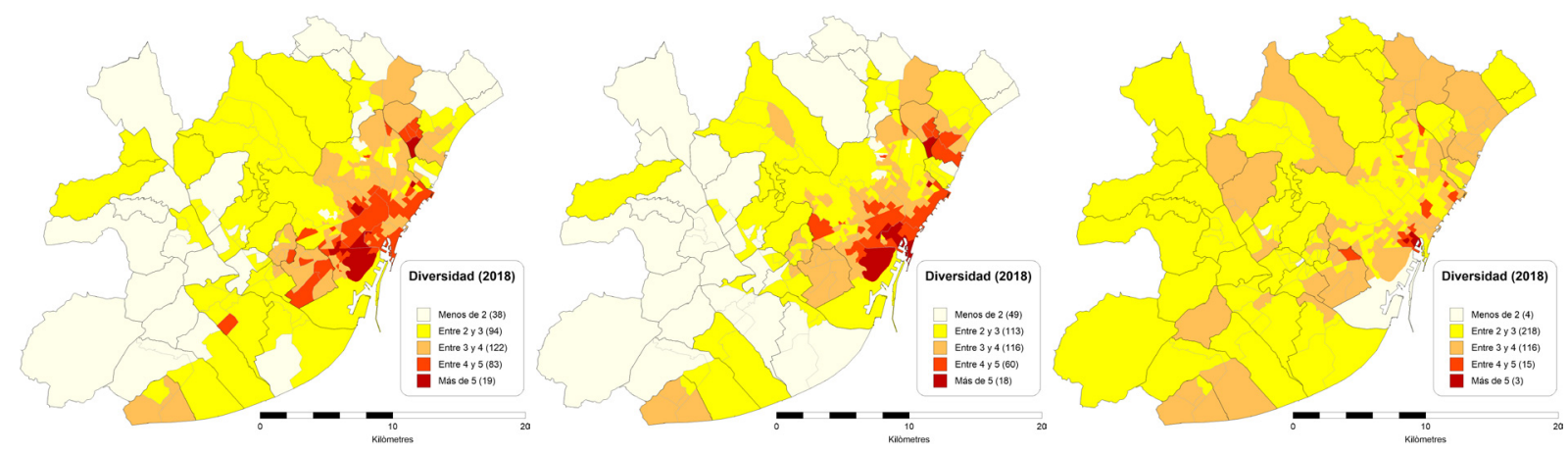

Fuente: Elaboración propia, Padrón de Población 2002, 2008 y 2018, con datos del Idescat. 
so de la diversidad tal y como está calculada, ya que la población nacida en el extranjero consigue ser mayoritaria, y con ello desciende la presencia ponderada de diversos orígenes, arrastrando con ello la pérdida de diversidad.

Los milennials, nacidos entre 1986-1990, son la generación que conoce un crecimiento de la diversidad más elevado entre 2008 y 2018, localizándose los espacios de mayor diversidad especialmente en el centro de Barcelona (en Ciutat Vella), o en la primera periferia metropolitana (en las ciudades de Santa Coloma de Gramenet y L'Hospitalet de Llobregat). También en estas tres zonas que destacan por su elevado número de residentes extranjeros, es donde la generación $\mathrm{X}$, nacida entre 1976-1980, alcanza los mayores índices de diversidad, por las mismas razones que la generación más reciente. Entre estos, y a diferencia de la generación anterior, la diversidad alcanzada es menor, como bien puede observarse cuando se compara lo que sucede a una misma edad (a los 28-32 años, por ejemplo). En contraste, la generación de los boomers de 1956-1960 muestra un crecimiento inferior y una mayor similitud territorial en las pautas de la diversidad en los tres momentos analizados. Al ser una generación más antigua a la que se añaden durante los últimos años pocos migrantes, el crecimiento de la diversidad ha resultado ser de menor magnitud. En este caso, y a diferencia de las generaciones posteriores, en las zonas menos pobladas de la periferia metropolitana la diversidad es siempre mayor. En contraste, los espacios donde la diversidad manifiesta sus valores máximos se circunscriben únicamente a unas pocas zonas, localizadas en el distrito de Ciutat Vella, y en concreto en los barrios Gótic y Raval (donde la migración internacional también era más antigua). Incluso entre 2008 y 2018 se verifica un decrecimiento de los espacios de mayor diversidad, de 21 que superan un valor de 4 a 18 en 2018, retroceso que no se produce en las otras dos generaciones analizadas.

Desde el punto de vista de las generaciones, las más recientes pues, están expuestos a una mayor diversidad -desde el punto de vista residencial-, al mismo tiempo que coexisten con zonas donde esta diversidad es muy baja. Esto significa la existencia de una mayor polarización territorial entre las generaciones más jóvenes por lo que a la diversidad se refiere, en comparación a generaciones más antiguas. Desde la perspectiva del territorio, el mayor grado de diversidad situado inicialmente en Ciutat Vella se consolida y extiende a la primera periferia metropolitana, mientras los municipios no centrales decrecen en los valores de diversidad. En estos últimos, se produce la paradoja de que la diversidad sigue siendo mayor entre las generaciones más antiguas.

Un ejemplo de la polarización antes mencionada se pone en evidencia en la Figura 7, donde se visibiliza que los espacios de menor diversidad en 2002 son más complejos que en 2018, en cuanto coexisten dos grupos con un peso muy superior al resto, los nacidos en el mismo municipio y los nacidos en España. En 2018, en cambio, más del $70 \%$ de los residentes son nacidos en el mismo municipio. Al mismo tiem-

FIGURA 7.

COMPOSICIÓN POR ORIGEN EN FUNCIÓN DEL GRADO DE DIVERSIDAD TERRITORIAL, 2002 Y 2018
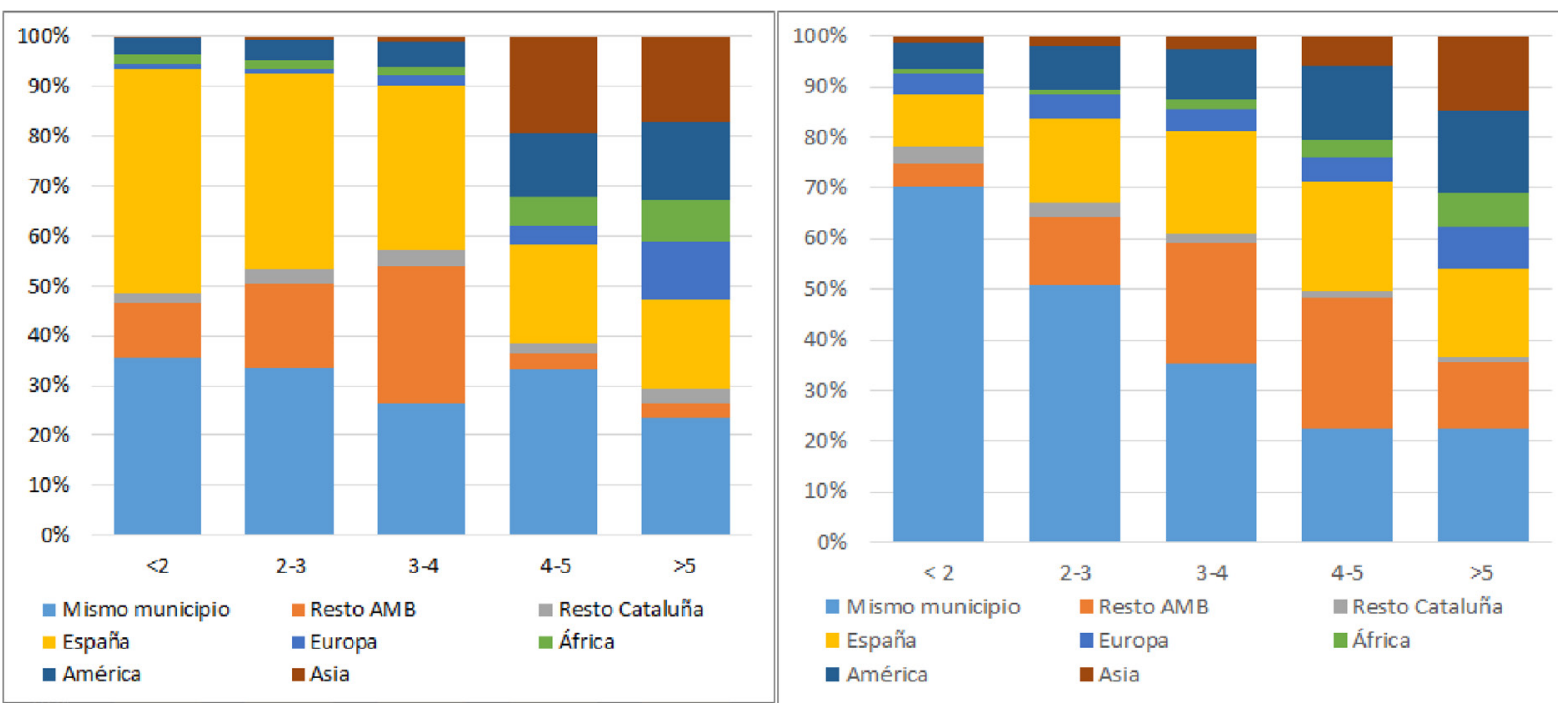

Fuente: Elaboración propia, Padrón de Población 2002 y 2018, con datos del Idescat. 
po, actualmente los espacios de mayor diversidad incorporan también una porción nada desdeñable de migrantes internos metropolitanos, en parte por un efecto localización de los mismos, ya que en 2002 estos espacios se circunscribían a Ciutat Vella, y en 2018 se añaden zonas de la primera corona metropolitana.

Las dos otras variables analizadas, nivel de estudios y relación entre sexos, también muestran diferencias remarcables al ser analizadas desde una perspectiva territorial, especialmente la primera. El nivel de instrucción se ha representado únicamente para las generaciones 1976-1980 y 1986-1990 en 2018 (con 3842 y 28-32 años respectivamente), y es quizás la variable más discriminante en el territorio, con un rango de posibilidades que dibuja una horquilla entre el mínimo del $8,4 \%$ al máximo del $80,4 \%$ de residentes con estudios superiores entre la generación de los milennials. Esta proporción manifiesta la enorme segregación social del espacio metropolitano (Rubiales, 2020; Nel·lo, 2018), con los distritos de Sarrià-Sant Gervasi, I'Eixample y Gràcia, más su prolongación hacia Sant Cugat del Vallès, como zonas donde el nivel de estudios es superior, y en los ejes de los ríos Besòs y Llobregat con los valores más bajos. El aumento general del nivel de instrucción de las generaciones jóvenes y la migración diferencial de aquellos con mejor nivel de estudios son factores que acrecientan las diferencias territoriales, de mayor envergadura que en épocas

FIGURA 8.

PROPORCIÓN DE RESIDENTES CON NIVEL DE ESTUDIOS SUPERIORES E ÍNDICE DE MASCULINIDAD PARA LAS GENERACIONES 1976-1980 Y 1986-1990, ÁREA METROPOLITANA DE BARCELONA, 2018.

Generación 1976-1980
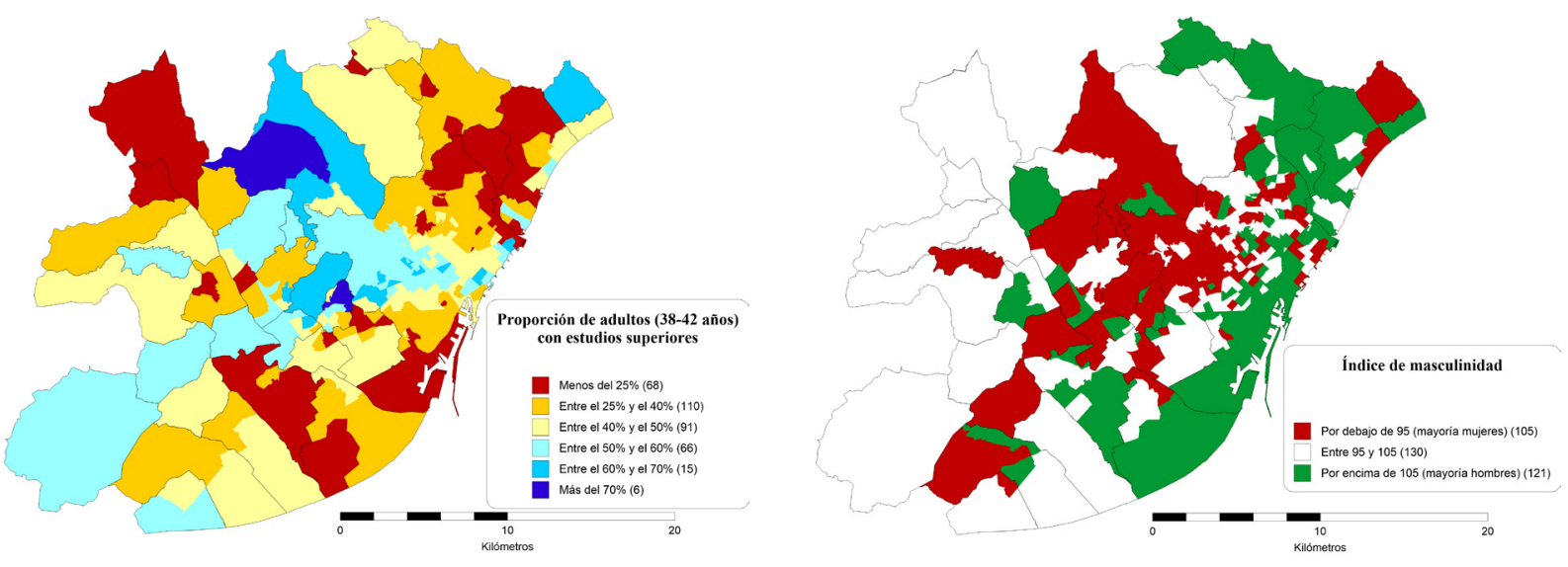

Generación 1986-1990
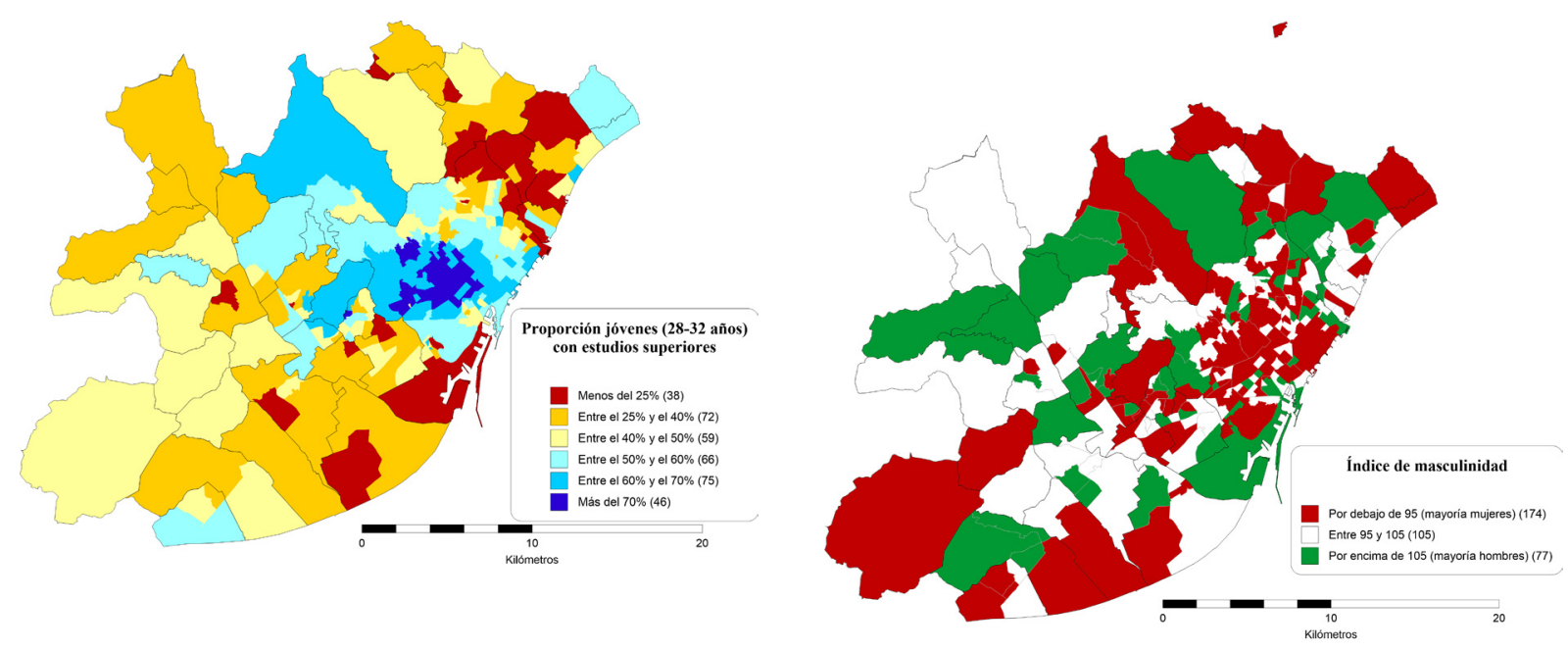

Fuente: Elaboración propia, con datos del Idescat. 
precedentes. Así, y calculando un índice de segregación ${ }^{3}$ para los que tienen nivel de estudios superiores, el indicador se acrecentaría del 0,243 de la generación boomer de 1976-1980 al 0,304 de la milennial de 1986-1990 para un mismo año 2018.

La comparación presentada en la Figura 8 muestra además como en algunos espacios metropolitanos las generaciones más antiguas, al contrario de lo que sucede en general, presentarían niveles de instrucción superiores que las generaciones más jóvenes. Lejos de apuntar un descenso generacional en el nivel de estudios, debemos buscar en las migraciones internas el factor explicativo de esta situación, que se produce en aquellas zonas habitadas por clases altas y localizadas fuera de la ciudad central, y donde el crecimiento de los efectivos generacionales debido a la migración habría experimentado un filtro por nivel de estudios.

En cuanto a la composición por sexo, las diferencias en el conjunto metropolitano se manifiestan de forma mucho más clara en el territorio, debido a la desigual localización residencial de algunos grupos de inmigrantes marcados por notables desequilibrios por sexo producto de las características de sus estrategias migratorias (Galeano y Bayona, 2018). De esta forma, si en la generación 1986-1990 un 50,8\% de sus componentes son mujeres, el abanico territorial es mucho mayor, y para la misma generación va de un $38,8 \%$ (en el distrito de Les Corts, pero con valores también bajos en el Raval y en el Besós) a un $61,5 \%$ (en el distrito de Horta-Guinardó, y también en el distrito de Gràcia) es decir, hasta 22,7 puntos porcentuales de distancia entre barrios en el territorio. En comparación a la generación 1976-1980, se observa una extensión de las zonas con mayor presencia de mujeres en la ciudad de Barcelona, en consonancia a la mayor feminización de los flujos migratorios antes comentada.

Existe, por lo tanto, una evidente disparidad territorial por origen, sexo y nivel de estudios, que evoluciona de forma particular según la generación, dando lugar a distintos ritmos en el cambio poblacional en el territorio. Para mostrar esta situación con mayor detalle y representar la convivencia entre generaciones se representan las pirámides de edad de los espacios de mayor diversidad en 2018 (aquellos con valores por encima de 5), distinguiendo entre su localización en el Centro, seleccionando las AEB de Ciutat Vella, y sumando los ejes del Besòs y del Llobregat, ya que muestran perfiles semejantes, tanto en los porcentajes de migrantes como en la vulnerabilidad (Fig. 9). En los espacios centrales de mayor

FIGURA 9.

ESTRUCTURA DE LA POBLACIÓN POR SEXO, EDAD, LUGAR DE NACIMIENTO Y NIVEL DE ESTUDIOS ALCANZADO, EN LAS SECCIONES DE MAYOR DIVERSIDAD SEGÚN SU LOCALIZACIÓN, 2018

Ciutat Vella

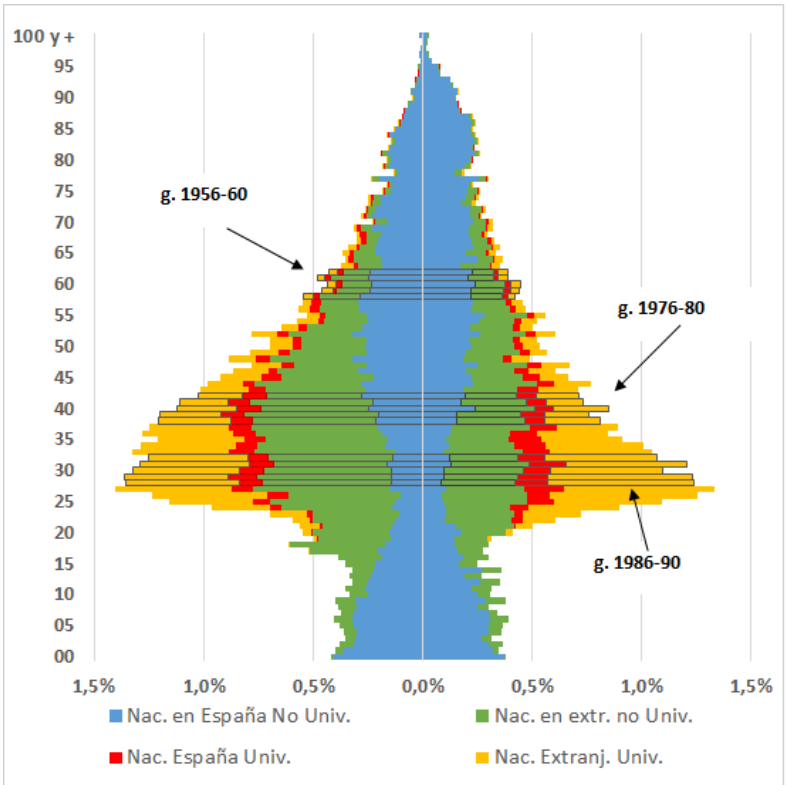

Ejes Besòs y Llobregat

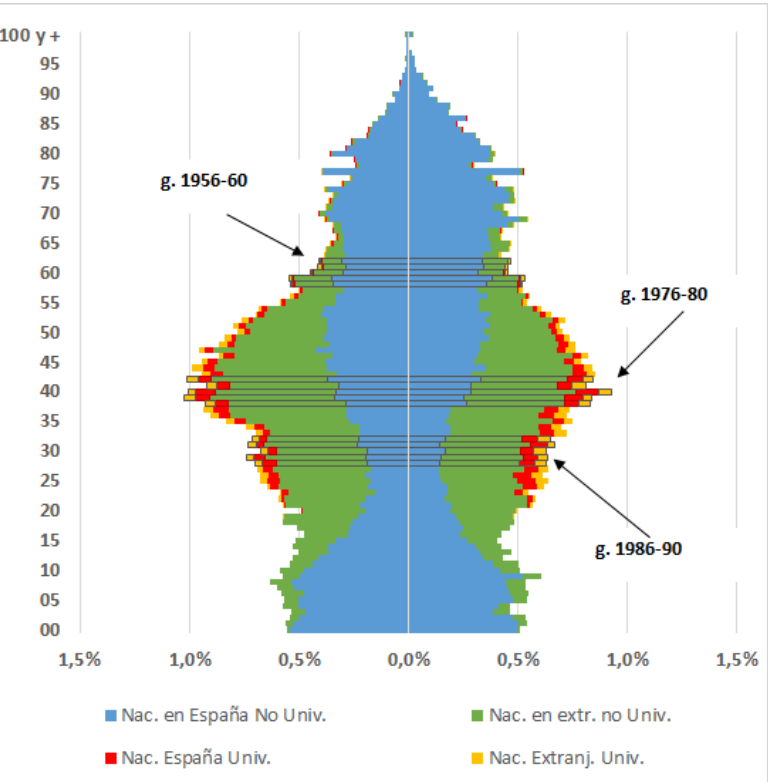

Fuente: Elaboración propia, con datos del Idescat. 
diversidad se ubican 49362 residentes, de los cuales el $55,4 \%$ es nacido en el extranjero, en el segundo se encuentran 68819 residentes, con el 39,3\% nacido fuera de España. A pesar de coincidir en concentraciones elevadas de inmigrantes, sus perfiles por sexo, edad y nivel de estudios muestran realidades distintas. En el Centro, la generación milennial ocupa la moda, mientras que en los ejes lo hace la Generación $X$, en ambas cohortes los inmigrados del extranjero son mayoría (un $80 \%$ y un $65 \%$ entre los milennials respectivamente, y un $67 \%$ y $58 \%$ entre la Generación $X$ en cada zona). En su conjunto las dos zonas muestran un mayor peso de los hombres, más pronunciado en Ciutat Vella $(53,2 \%)$ que en las secciones de los mencionados ejes $(50,4 \%)$, a pesar de la feminización de las pirámides en las edades mayores como consecuencia de un envejecimiento, monopolizado por la población autóctona. En el extremo opuesto de la pirámide, destaca la mayor base de los ejes, que se corresponde con un volumen considerable de menores que, aunque nacidos en España, en una proporción elevada son descendientes de extranjeros. Pero la diferencia más reveladora al considerar ambas estructuras se debe al nivel de estudios, mientras en el Centro de la ciudad más de un tercio de los inmigrados tienen estudios superiores (el 37,6\% de todos los nacidos en el extranjero), en los Ejes del Llobregat y el Besòs sólo lo poseen el 7,1\%. En ambos casos superan el porcentaje de estudios universitarios entre los autóctonos residentes en las mismas zonas $(14,5 \%$ y $5,9 \%$ respectivamente), siendo una situación especialmente visible entre los más jóvenes: si la generación 1986-1990 muestra un $53,7 \%$ de estudios universitarios, la generación $1976-1980$ un 36,9\% y la 1956-1960 un 23,4\% en Ciutat Vella. Estos jóvenes con estudios universitarios muestran una composición heterogénea por lugar de nacimiento, desde europeos comunitarios (franceses, italianos, británicos o alemanes), a latinoamericanos (argentinos, colombianos, venezolanos y chilenos), filipinos o marroquíes, estos últimos colectivos ya presentes en el territorio donde los nuevos flujos presentan un cambio importante en el nivel de estudios en comparación a flujos precedentes.

Las diferencias de género son también significativas, ya que los inmigrados sin estudios son mayoritariamente hombres (el $60,7 \%$ ), mientras adquieren mayor peso las mujeres cuando se ha alcanzado un nivel de estudios superior (el 51,1\%). Así, la diversidad en el Centro de la ciudad es mayor si se consideran sexo y nivel de estudios, con inmigrantes extranjeros muy jóvenes y con elevado nivel de estudios, conviviendo con inmigrados sin estudios en su mayoría hombres, más una población autóctona envejecida, feminizada y con bajo nivel de estudios en general. En cambio, en los ejes del Besós y Llobregat la pirámide muestra una estructura con menor peso de los jóvenes, más envejecida, con un máximo de efectivos entre 15 y 20 años por encima de la pirámide anterior (alrededor de los cuarenta años de edad), y con un perfil por estudios más similar entre unos y otros.

\section{CONCLUSIONES: LA MIGRACIONES Y EL CAMBIAN- TE PULSO DEMOGRÁFICO METROPOLITANO}

Lejos del esperado decrecimiento con la edad, gracias a las migraciones la mayoría de las generaciones más jóvenes presentes actualmente en el contínuum urbano de la ciudad de Barcelona ha conocido un crecimiento de su volumen, llegándose incluso a duplicar los efectivos iniciales en algunas ocasiones. Pero más allá del número, este aumento de efectivos lleva asociado un crecimiento de la heterogeneidad intra e intergeneracional, si atendemos a lo que sucede según el lugar de nacimiento, el nivel de estudios alcanzado y el equilibrio entre sexos, que han sido las tres variables explotadas en este trabajo. Como resultado, las distintas generaciones que conviven en un mismo territorio son cada vez más disimilares, sea cual sea la variable analizada. La adaptación de las generaciones a los diferentes fenómenos demográficos, y en general socioeconómicos, marcan también el pulso metropolitano.

En el caso del origen, el crecimiento de la heterogeneidad por lugar de nacimiento es evidente. Por un lado, encontramos unas generaciones mayores de boomers relativamente homogéneas respecto a su origen, con pocas diferencias en el territorio, y con variaciones que únicamente dependen de antiguas migraciones interiores; por el otro, a unas generaciones jóvenes donde se multiplican los orígenes y con ellos la heterogeneidad. Esa creciente heterogeneidad por origen se ha traducido en el territorio para las diferentes generaciones en una mayor diversidad, cuando entraban en contacto con otros orígenes de forma ponderada, o con una relativa diversidad cuando se daban situaciones de polarización, donde unos pocos grupos pesaban mucho más que el resto. En el nivel de estudios encontramos un poderosos crecimiento de los jóvenes con estudios superiores, contrastando con las generaciones mayores donde esta situación era minoritaria, diferencias que en esta ocasión son muy claras en el espacio metropolitano, donde se produce un crecimiento de la segregación: producto tanto de la reproducción de las 
desigualdades como de la selección de los residentes por nivel de instrucción. Aunque la atracción de perfiles de ocupación con bajo nivel de estudios haya sido un factor determinante en la inmigración en el AMB, difiere mucho en conjunto según las generaciones. $A$ generaciones más jóvenes, también entre los migrantes, aumenta la proporción de aquellos con estudios universitarios, aumentando asimismo la diversificación de los migrantes por razón de estudios, polarizándose incluso para las mismas edades, aunque siempre con mejor posición de las mujeres sobre los hombres. Finalmente, y como consecuencia del perfil de los últimos flujos migratorios llegados, pero en menor medida de flujos pasados, las diferencias entre efectivos por sexo llegan incluso a revertirse, con una mayor presencia de mujeres asociada a las edades de mayor llegada inicial de inmigrantes internacionales. Al mismo tiempo, debemos considerar cómo estas diferencias entre generaciones se encuentran en valores que pueden ser considerados como máximos históricos, como lo demuestran los cálculos de la diversidad para los mayores de 70 años en comparación con las generaciones más recientes, distancia que en un futuro posiblemente disminuirá, ya que las generaciones mayores se irán haciendo cada vez más diversas con el paso del tiempo.

Desde la perspectiva del territorio, los cambios generacionales llevan consigo un crecimiento de la polarización mostrando intensas diferencias entre la ciudad de Barcelona y los municipios más alejados, y en el propio centro, entre los distintos barrios de la ciudad. La diversidad es un atributo que acompaña a las zonas con mayor número de inmigrados, aunque esta afirmación parece de por sí evidente, pero no lo es. Recuérdese que la diversidad mide de forma ponderada la representación de distintos grupos poblacionales por origen y no solo el porcentaje de nacidos en el extranjero o de extranjeros en ese mismo origen. Así, la polarización y los problemas que puede conllevar a la convivencia, es un fenómeno más frecuente en barrios con rangos de concentración de extranjeros menores. Incluso en zonas de elevada proporción de inmigración internacional y de alta diversidad como los dos ejemplos analizados, localizados en Ciutat VeIla y en el Eje del rio Besòs y el del Llobregat, ambas caracterizadas por su vulnerabilidad, las características de las generaciones que residen en ellas tanto las autóctonas, como sobre todo las inmigradas -debido a la antigüedad de los flujos-, no son equiparables; posiblemente tampoco lo sean las dinámicas de interacción que se dan entre los grupos -por razón de edad, de origen pero también de género-, y las demandas que plantean a la administración pública. EI análisis generacional en estos barrios por origen nos muestra una realidad impactante: más de la mitad de sus integrantes ha nacido en el extranjero -el $80 \%$ entre los millenials que viven en el Centro de Barcelona-, y posiblemente buena parte de los nacidos en España sean ya descendientes de inmigrados internacionales, lo que podría tener consecuencias tanto en la identidad territorial de la generación y de esos mismos individuos, como en la del mismo barrio, teniendo en cuenta la apropiación del espacio que realizan esas generaciones más recientes. Sin embargo, atendiendo tanto a su diversidad por orígenes como a los elevados niveles de instrucción, nada tienen que ver con la imagen que se ha ido construyendo sobre esos barrios -y que tememos sigue pesando en la administración-.

La deficiente calidad de los datos por año de llegada nos ha impedido el análisis de la renovación poblacional en los barrios como era nuestra pretensión, queda pendiente, pues, afinar la medición del metabolismo demográfico en el territorio. Por otro lado, viendo la estructura por edades y el origen de la población, podemos anticipar que uno de los impactos de la Covid-19 en las zonas analizadas, va a ser una aceleración del metabolismo demográfico debido a la incidencia de la mortalidad en las generaciones mayores, pero sobre todo a la circulación de vivienda que estos óbitos van a provocar, haciendo visible el factor de mercado que se oculta tras la substitución de las generaciones. Muy posiblemente en el año 2020, bajo los efectos de la pandemia y los dos siguientes, se haya producido una escalada significativa en la proporción de personas inmigradas en territorios como el conglomerado que forman los ejes del Besòs y el Llobregat.

\section{RECONOCIMIENTOS}

Este texto se inscribe en el proyecto de investigación "Metabolismo demográfico, migraciones y cambio social en España" (PID2020-113730RB-I00), financiado por el Ministerio de Ciencia e Innovación y con Andreu Domingo y Jordi Bayona como investigadores principales.

\section{NOTAS}

1 No se dispone para todos los años de los datos censales por edades a escala municipal, a excepción de la ciudad de Barcelona, lo que no nos permite reconstruir el Área Metropolitana. Es por ello que se realiza el análisis para el ámbito provincial.

2 Este dato proviene del Padrón Continuo de Población, siendo una variable que a pesar de su pro- 
gresiva mejora en su cobertura por el cruce de registros administrativos puede aún mostrar valores inferiores a los reportados por otros recuentos, como el Censo de población.

3 El índice de segregación se calcula empleando la formulación siguiente: $I S=\frac{1}{2} \sum_{i=1}^{n}\left|\frac{\mathrm{x}_{\mathrm{i}}}{\mathrm{x}}-\frac{\mathrm{t}_{\mathrm{i}}-\mathrm{x}_{\mathrm{i}}}{\mathrm{T}-\mathrm{x}}\right|$, siendo $\mathrm{x}$ el nivel de estudios universitarios y $\mathrm{t}$ el total de población en las unidades espaciales i.

\section{REFERENCIAS BIBLIOGRÁFICAS}

Albaigés, B. y Ferrer-Esteban, G. (2012). L'èxit educatiu a Catalunya. Indicadors dels sistemas educatius. L'estat de l'educació a Catalunya. Anuari 2011. Barcelona, España. Fundació Jaume Bofill, col. Polítiques, 76.

Andersen, R. y Fetner, T. (2008). Cohort Differences in Tolerance of Homosexuality Attitudinal Change in Canada and the United States, 1981-2000. Public Opinion Quartely, 72 (2): 311-330. doi: https:// doi.org/10.1093/poq/nfn017

Bayona, J., Domingo, A. y Menacho, T. (2020). Trayectorias migratorias y fracaso escolar de los alumnos inmigrados y descendientes de migrantes en Cataluña. RIS, Revista Internacional de Sociología, 78(1): e150. doi: https://doi.org/10.3989/ ris.2020.78.1.18.107

Bayona, J. y Pujadas, I. (2014). Movilidad residencial y redistribución de la población metropolitana: Los casos de Madrid y Barcelona. EURE: Revista Latinoamericana de Estudios Urbanos y Regionales, 40 (119), 261-287. doi: https://doi.org/10.4067/ s0250-71612014000100012

Brooks, C. y Bolzendahl, C. (2014). The Transformation of US Gender Role Attitudes: Cohort Replacement, Social Structural Change and Ideological Learning. Social Science Research, 33 (1): 106-33. doi: https://doi.org/10.1016/S0049089x(03)00041-3

Cabré, A. y Pujadas, I. (1987). La fecundidad en Cataluña desde 1922: Análisis y perspectivas. Papers de demografia, 20.

Coleman, D. (2006). Immigration and ethnic change in low-fertility countries, A Third demographic transition. Population and Development Review, Vol. 32 (3): 401-446. Doi: https://doi.org/10.1111/ j.1728-4457.2006.00131.x

Coleman, D. y Basten, S. (2015). The Death of the West: An alternative view. Population Studies, 69
(Issue sup. 1: Population the Long View): S107S118. DOI: 10.1080/00324728.2014.970401

Easterlin, R. A. (1980) Birth \& Fortune. The impact of the number on the Individual Welfare. London, Grant Mclntyre.

Feixa, C. (2021). Generación Blockchain: movimientos juveniles en la era de la web semàntica. Revista Latinoamericana de Ciencias Sociales, Niñez y Juventud, 19 (1):1-20. Doi: https://orcid.org/00000002-4874-1604

Galeano, J. y Bayona, J. (2018). Residential Segregation and clustering dynamics of migrants in the metropolitan area of Barcelona: A demo-spatial analysis at the census tract level. Revue Quetelet, v. 6(1), pp. 99-127, DOI:10.14428/rqj2018.06.01.05

Galeano, J. y Bayona, J. (2016). La diversidad en las metròpolis españolas. En A. Domingo (Ed.) Inmigración y diversidad en España. Crisis económica y gestión municipal. Barcelona, España: Editorial Icària. Col. Ак $\alpha \eta \mu \varepsilon \iota \alpha$. Procesos Migratorios. ISBN: 978-84-9888-726-6, p. 49-74.

Goujon, A., Skirbekk, V., Fliegenschnee, K. y Strzelecki, P. (2006). New Times, Old Beliefs: Projecting the Future Size of Religions in Austria. Working Papers, of Viena Institute of Demography, núm. 01/2006.

Gutiérrez, A. y Delclós, X. (2015). ¿Hipertrofia inmobiliaria? Análisis de las pautas territoriales del boom e implicaciones del estallido de la burbuja en Cataluña. Cuadernos Geográficos, 54 (1), 283-306. DOI: https://doi.org/10.30827/cuadgeo.v54i1.2527

López, A., Sales, J., Solana, M., Fernández, A. y Peralta, A. (2019). Midiendo los procesos de gentrificación en Barcelona y Madrid: una propuesta metodológica. En XIII CTV 2019 Proceedings: XIII International Conference on Virtual City and Territory: "Challenges and paradigms of the contemporary city": UPC, Barcelona, October 2-4, 2019. Barcelona: CPSV, 2019, p. 8680. E-ISSN 2604-6512. DOI: http://dx.doi.org/10.5821/ctv.8680

Lutz, W. (2012). Demographic Metabolism: A Predictive Theory of Socioeconomic Change. Population and Development Review, Vol. 38 Population and Public Policy: Essays in Honor of Paul Demeny (suplement), 283-301. DOI:10.1111/J.1728-4457.2013.00564.X

Lutz, W., Butz, W. P. y Samir CK. (2014). World Population and Human Capital in the Twenty-First Century. Oxford: Oxford University Press. 
Lutz, W. y Muttarak, R. (2017). "Forecasting Societies" Adaptative Capacities through a Demographic Metabolism Model. Nature Climate Change, 7 (3), 177184. Doi: https://doi.org/10.1038/nclimate3222

Mannheim, K. (1993) [1928]. El problema de las generaciones. Revista Española de Investigaciones Sociológicas, 62 (93), 193-242.

Módenes, J. A. y López-Colás, J. (2014). Cambio demográfico reciente y vivienda en España ¿hacia un nuevo sistema residencial? Revista Española de Investigaciones Sociológicas, 148, octubre-diciembre, 103-144. Doi: http://dx.doi.org/10.5477/cis/reis.148.103

Myers, D. y Ryu, S. H. (2008). Aging Baby Boomers and the Generational Housing Bubble: Foresight and Mitigation of an Epic Transition. Journal of the American Planning Association, (1): 1-17. Doi: https://doi.org/10.1080/01944360701802006

Nel·lo, O. (2018). Hacer la ciudad metropolitana: segregación residencial y políticas urbanas en el ámbito metropolitano de Barcelona. Ciudad y territorio, estudios territoriales, 198, 697-715.

Ortega, E. y Solana, M. (2015). Migracions a Catalunya: cinc decades de canvis i continuïtats. En: A. Domingo (Coord.) Migracions dels segles XX i XXI: una mirada candeliana, Collecció Ciutadania i Immigració, n. 11, p. 43-64.

Pampel, F. C. (2016). Cohort Change in the Social Distribution of Tolerant Sexual Attitudes. Social Forces, 95 (2), 753-777. Doi: https://doi.org/10.1093/sf/ sow069

Pew Research Center (2015). The Future of World Religions: Population Growth Projections, 20102050. https://assets.pewresearch.org/wpcontent/ uploads/sites/11/2015/03/PF_15.04.02_ProjectionsFullReport.pdf
Pujadas, I. (2007). Les migracions dels anys seixanta a Catalunya. En Centre d'Estudis Demogràfics (Coord.) Nadala 2007. Immigració. Les onades immigratòries en la Catalunya contemporània. Barcelona, España: Fundació Lluís Carulla, p. 35-48.

Pujadas, I., Bayona, J., Gil-Alonso, F. y López, C. (2013). Pautas territoriales de la fecundidad en la Región Metropolitana de Barcelona (1986-2010). Estudios Geográficos, vol. LXXIV (275), p. 585-609. doi:10.3989/estgeogr.201321.

Rubiales, M. (2020). Segregación en las metrópolis españolas 2001-2011: un análisis con detalle territorial. Documents d'Anàlisi Geogràfica, 66, n. 1, p. 83-105. (doi:10.5565/rev/dag.581).

Ryder, N. (1965). The cohort as a concept in the study of social change. American Sociological Review, 30(6): 843-861. Doi: http://dx.doi. org/10.2307/2090964

Simpson, E. H. (1949). Measurement of diversity. Nature, 163, p. 688-688.

Striessnig, E. (2019). The Demographic Metabolism Model of Human Capital Formation. En: A. Bacci, K., Prettner y A. Prskawetz (Eds.) Human Capital and Economic Growth. The Impact of Health, Education and Social Change. New York, EUA: Palgrave Macmillan, pp. 139-165.

Striessnig, E. y Lutz, W. (2016). Demographic Strengthening of European Identity. Population and Development Review, 42 (2): 305-311. Doi: https:// doi.org/10.1111/j.1728-4457.2016.00133.x

White, M.J. (1986). Segregation and Diversity Measures in Population Distribution. Population Index, v. 52 (2), p. 198-221. Doi: https://doi. org/10.2307/3644339 